\title{
Catalytic and Noncatalytic Conversion of Methane to Olefins and Synthesis Gas in an AC Parallel Plate Discharge Reactor
}

\author{
Mohammad Ali Khodagholi and Mohammad Irani \\ Gas Division, Research Institute of Petroleum Industry, West Boulevard Azadi Sport Complex, 14665-1998 Tehran, Iran \\ Correspondence should be addressed to Mohammad Ali Khodagholi; khodagholima@ripi.ir
}

Received 27 January 2012; Accepted 4 June 2012

Academic Editor: Guochuan Yin

Copyright (C) 2013 M. A. Khodagholi and M. Irani. This is an open access article distributed under the Creative Commons Attribution License, which permits unrestricted use, distribution, and reproduction in any medium, provided the original work is properly cited.

\begin{abstract}
Direct conversion of methane to ethylene, acetylene, and synthesis gas at ambient pressure and temperature in a parallel plate discharge reactor was investigated. The experiments were carried out using a quartz reactor of outer diameter of 9 millimeter and a driving force of ac current of $50 \mathrm{~Hz}$. The input power to the reactor to establish a stable gas discharge varied from 9.6 to maximum 15.3 watts $(\mathrm{w})$. The effects of ZSM5, Fe-ZSM5, and Ni-ZSM5 catalysts combined with corona discharge for conversion of methane to more valued products have been addressed. It was found that in presence or absence of a catalyst in gas discharge reactor, the rate of methane and oxygen conversion increased upon higher input power supplied to the reactor. The effect of Fe-ZSM5 catalyst combined with gas discharge plasma yields $\mathrm{C}_{2}$ hydrocarbons up to $21.9 \%$, which is the highest productions of $\mathrm{C}_{2}$ hydrocarbons in this work. The effect of combined Ni-ZSM5 and gas discharge plasma was mainly production of synthesis gas. The advantage of introducing ZSM5 to the plasma zone was increase in synthesis gas and acetylene production. The highest energy efficiency was $0.22 \mathrm{mmol} / \mathrm{kJ}$, which belongs to lower rate of energy injection to the reactor.
\end{abstract}

\section{Introduction}

Although methane is an excellent raw material for production of fuels and chemicals, still its main use is as fuel for power generation and for domestic and industrial use. In many respects, methane is an ideal fuel for these purposes because of its availability in most populated centres, its ease of purification to remove sulphur compounds, and the fact that among the hydrocarbons, it has the largest heat of combustion relative to the amount of $\mathrm{CO}_{2}$ formed. On the other hand, methane is a greatly underutilized resource for chemicals and liquid fuels [1]. Methane can be converted to chemicals and fuels in two ways, either via synthesis gas or directly into $\mathrm{C}_{2}$ hydrocarbons or methanol. Almost all commercial processes for large-scale natural gas conversion involve synthesis gas production. Steam reforming is the dominant process for production of synthesis gas $[2,3]$ at high input energy as is shown in

$$
\begin{aligned}
& \mathrm{CH}_{4}+\mathrm{H}_{2} \mathrm{O} \longleftrightarrow \mathrm{CO}+3 \mathrm{H}_{2} \\
& \Delta \mathrm{H}^{0} 298 \mathrm{~K}=206 \mathrm{~kJ} / \mathrm{mol}
\end{aligned}
$$

The synthesis gas $\left(\mathrm{CO}+\mathrm{H}_{2}\right)$ is converted to higher hydrocarbons or fuels via Fischer-Tropsch (FT) synthesis. The catalysts employed are based mainly on cobalt and iron at pressures as high as 22 bars and temperatures of higher than $560 \mathrm{~K}[4,5]$.

To reduce energy costs it is possible to use electric power in a plasma process instead of thermal processing. In most of gas discharge plasma, free molecular radicals generated by excitation, dissociation, and ionization of gas molecules are essential for the subsequent free radical reactions. Control of electron energy by suitable design of discharge reactor and mode of gas discharge may lead to favorable products. Non-thermal plasmas at ambient temperature and pressure recently are being investigated as the promising alternative to convert methane to $C_{2}$ hydrocarbons [6-15].

In gas discharge plasma the main electrical energy is transferred to energetic electrons and active radical species rather than simple gas heating. As electrons possess minor mass compared to heavy ions they gain much higher speed in an electric field consequently they are in higher temperature state too. The electrons in a gas discharge collide with gas molecules and impart whole or a portion of their kinetic 
energy to exit the molecules to a higher energy states. Ultimately the molecule of the gas dissociates to radicals and other species and gives rise to synthesis of new products [16].

Recently zeolites have been found to be active for low temperature of methane conversion to higher hydrocarbon. Investigation of metal-substitute H-ZSM5 catalysts has also been reported [6]. In general low temperature methane conversion over zeolites has progressed in two directions: one is the modification of the performance of the zeolite as the support and the other is the modification of supported metal properties. Some mechanistic analyses have been presented $[17,18]$. Relevant to these studies are the properties of zeolites related to their specific electronic structure. It is possible that the catalytic properties of a zeolite might be altered if it were electrically charged. No higher hydrocarbon activity was observed over this catalyst in the absence of corona discharge at any temperature up to $800^{\circ} \mathrm{C}$. Charged catalytic activity obtained by the interaction of a corona discharge with a zeolite catalyst has led to low temperature methane conversion.

Due to its unique shape selectivity, solid acidity, ion exchangeability, pore size, thermal stability and structural network, ZSM-5 has been widely used as catalysts and sorbents in petroleum and petrochemical industry.

In this study methane conversion to olefins and synthesis gas using parallel plate discharge plasma is investigated. The experiments were performed over H-ZSM5 and its Fe and Ni substitute promoted catalyst. The effects of input power on methane and oxygen conversion and products selectivity are studied. Ultimately the yield of higher hydrocarbons and energy efficiency of the present work are evaluated.

\section{Experimental}

The schematic experimental setup used in this research is shown in Figure 1. The reactor was a quartz tube of $7 \mathrm{~mm}$ outer diameter (O.D) and $0.25 \mathrm{~mm}$ wall thickness. The electrodes are two similar stainless steel circular discs with $6.5 \mathrm{~mm}$ outer diameter and $2 \mathrm{~mm}$ thickness. The bottom electrode was kept at the potential of zero that is, was grounded and the upper electrode at different potentials. In all experiments performed methane and oxygen were mixed with helium as it helps the stability of gas discharge. In higher applied voltages to the reactor there were some liquid products collected in condenser which was kept it away without analysis.

\section{Catalyst Preparation}

Fe-ZSM5 was prepared by solid state ion exchange method, $\mathrm{H}$-ZSM5 (zeolyst Intel. with $\mathrm{Si} / \mathrm{Al}=50$ ) was mixed with $\mathrm{FeCl}_{2}$ in a ball mill for 75 minutes. The zeolite to iron chloride weight ratio was $2: 1$. The calcinations of the resulting powder was performed at $560^{\circ} \mathrm{C}$ for 5 hours, washed with De-ionized water to remove the anions and dried at $100^{\circ} \mathrm{C}$ for $16 \mathrm{~h}$.

The ZSM-5 supported Ni catalysts were prepared by incipient wetness impregnation method using aqueous nitrates solution (Aldrich) as Ni precursors. Nickel nitrates,
$\mathrm{H}$-ZSM5 and water were thoroughly mixed at $60^{\circ} \mathrm{C}$ for 3 hours, dried at $120^{\circ} \mathrm{C}$ for 6 hours, followed by calcinations at $600^{\circ} \mathrm{C}$ during 5 hours in oxygen rich gas conditions. Reduction of catalyst was done by flowing hydrogen at $650^{\circ} \mathrm{C}$ for 1 hour.

The calcinations of $\mathrm{H}-\mathrm{ZSM} 5$ were completed at $560^{\circ} \mathrm{C}$ in a tubular furnace for 6 hours in a flow of air. Table 1 represents the physical characteristics of the three catalysts used in the performed experiments.

The following relations were used to determine the different parameters.

$$
\begin{gathered}
\mathrm{CH}_{4} \text { conversion }=\left(\frac{\text { moles of } \mathrm{CH}_{4} \text { consumed }}{\text { moles of } \mathrm{CH}_{4} \text { introduced }}\right) \times 100 \\
\mathrm{O}_{2} \text { conversion }=\left(\frac{\text { moles of } \mathrm{O}_{2} \text { consumed }}{\text { moles of } \mathrm{O}_{2} \text { introduced }}\right) \times 100
\end{gathered}
$$$$
\text { Selectivity of } \mathrm{C}_{2} \mathrm{H}_{6}=2 \times\left(\frac{\text { moles of } \mathrm{C}_{2} \mathrm{H}_{6} \text { formed }}{\text { moles of } \mathrm{CH}_{4} \text { consumed }}\right)
$$$$
\times 100
$$

Selectivity of $\mathrm{C}_{2} \mathrm{H}_{4}=2 \times\left(\frac{\text { moles of } \mathrm{C}_{2} \mathrm{H}_{4} \text { formed }}{\text { moles of } \mathrm{CH}_{4} \text { consumed }}\right)$

$$
\times 100
$$

$$
\text { Selectivity of } \begin{aligned}
\mathrm{C}_{2} \mathrm{H}_{2}= & 2 \times\left(\frac{\text { moles of } \mathrm{C}_{2} \mathrm{H}_{2} \text { formed }}{\text { moles of } \mathrm{CH}_{4} \text { consumed }}\right) \\
& \times 100
\end{aligned}
$$

Yields of $\mathrm{C}_{2}$ hydrocarbons

$$
\begin{gathered}
=\mathrm{CH}_{4} \text { conversion } \\
\qquad \sum\left(\text { Selectivities of } \mathrm{C}_{2} \mathrm{H}_{6}, \mathrm{C}_{2} \mathrm{H}_{4}, \mathrm{C}_{2} \mathrm{H}_{2}\right) \\
\text { Energy Efficiency }=\frac{\text { Moles of } \mathrm{CH}_{4} \text { Converted }(\mathrm{mol} / \mathrm{s})}{\text { Energy Injected }(\mathrm{w})}
\end{gathered}
$$

\section{Results and Discussion}

The experiments were carried out in atmospheric pressure and room temperature keeping the total feed to the reactor for all experiments at $100 \mathrm{~mL} /$ minute in which the net methane flow rate was $16 \mathrm{~mL} / \mathrm{minute}$ with methane to oxygen ratio as $4 / 1$. First the feed was sent to the reactor under the plasma action only. In order to investigate the effect of prepared catalysts for converting of methane and oxygen, 0.45 gram of each catalyst H-ZSM5, Fe-ZSM5 and Ni-ZSM5 were separately loaded to the reactor. One of the catalysts was tested at a time, subsequently the reactor was cleaned and the next catalyst was loaded. For each of the catalysts an experiment was performed without the action of plasma, the analysis of results however indicate that there was no any new component in effluent gases from the reactor than the feed to the reactor up to $200^{\circ} \mathrm{C}$. In all the experiments the reactor was never heated by external heaters but in some instances due to 


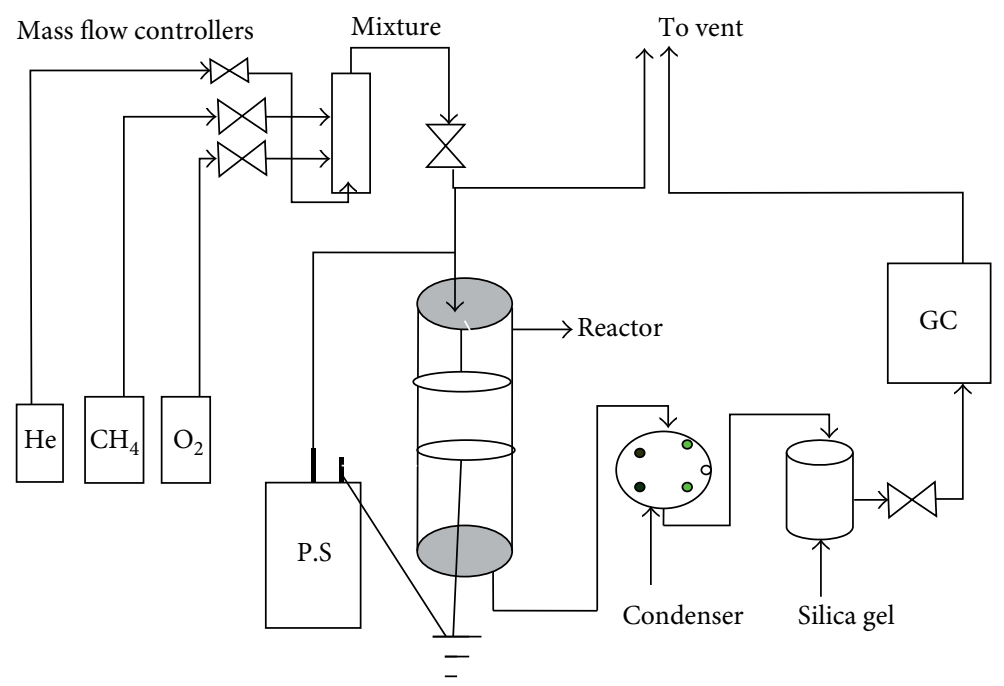

FIgure 1: Platform of Corona Discharge with Feed and Analysis systems.

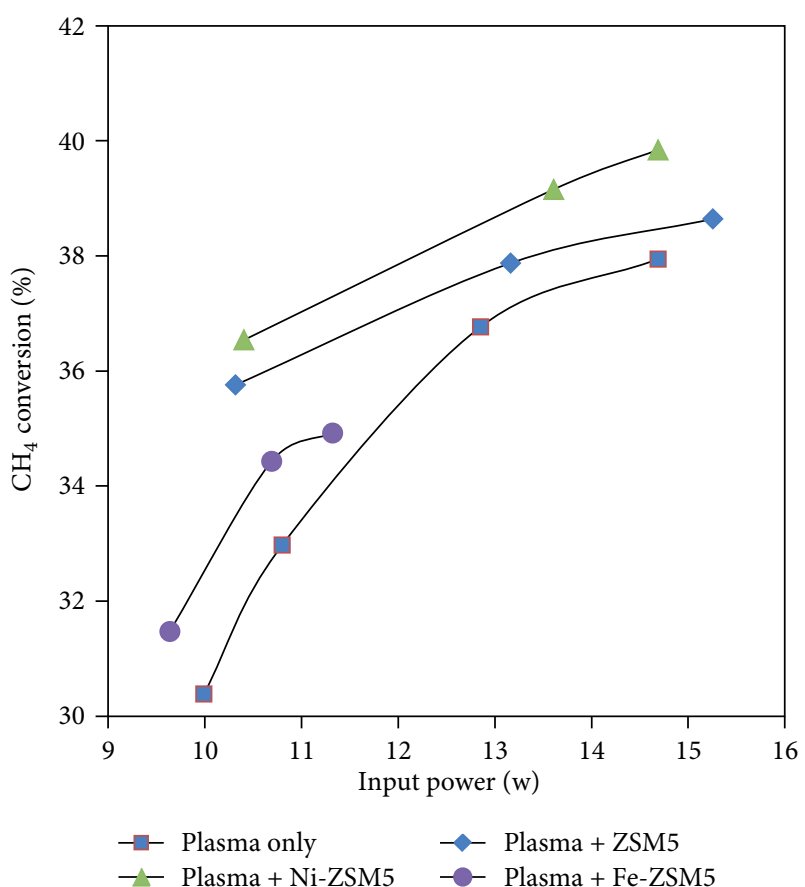

FIgURE 2: Methane conversion versus power consumed in the reactor.

the conversion of a portion of input electrical energy to heat and release of heat due to exothermic reactions taking place in the plasma zone the wall of the reactor was at temperatures close to $150^{\circ} \mathrm{C}$.

The conversions of methane and oxygen verses input power applied to the reactor are shown in Figures 2 and 3. The conversion of $\mathrm{CH}_{4}$ and $\mathrm{O}_{2}$ increased upon increase in input of electrical power to the reactor. The Ni-ZSM5 shows the most significant effects in converting methane and oxygen as high as to $40 \%$ and $48.3 \%$ respectively. The effect of $\mathrm{Fe}$ ZSM5 catalyst is interesting as the stable gas discharge plasma

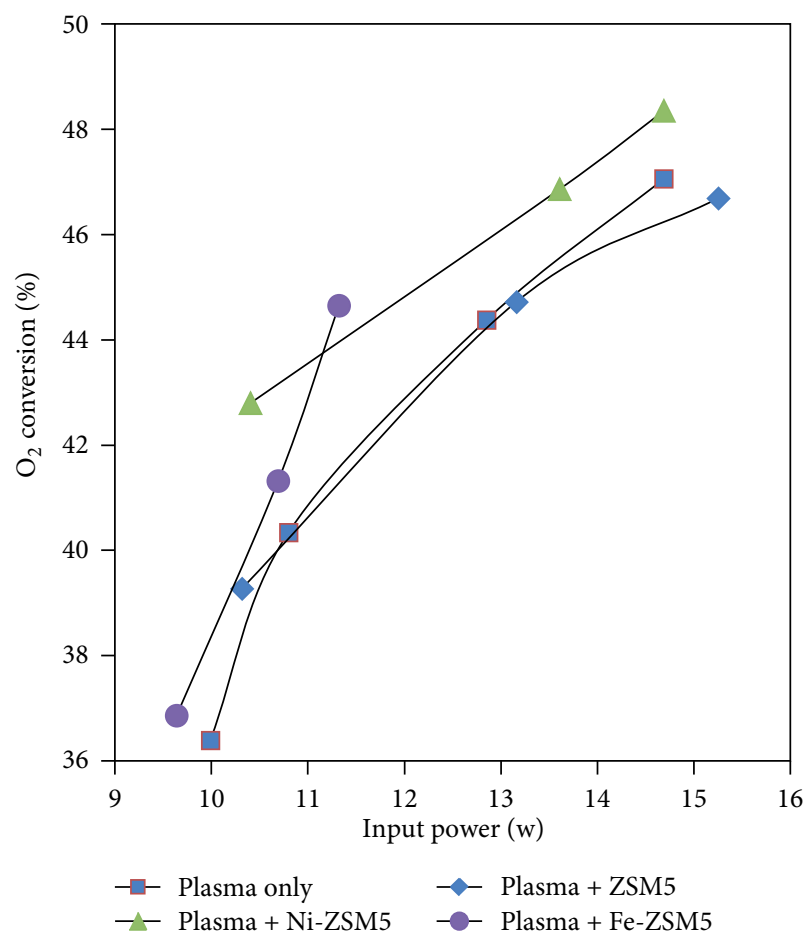

Figure 3: Oxygen conversion versus power consumed in the reactor.

TABLE 1: Textural properties of prepared catalysts.

\begin{tabular}{lcccc}
\hline Catalyst & BET $\left(\mathrm{m}^{2} / \mathrm{g}\right)$ & Pore volume $\left(\mathrm{cm}^{3} / \mathrm{g}\right)$ & $\mathrm{Si} / \mathrm{Al}$ & $\mathrm{wt} \%$ metal \\
\hline ZSM5 & 354 & 0.11 & 28 & 0 \\
Fe-ZSM5 & 349 & 0.10 & 28 & 3 \\
Ni-ZSM5 & 350 & 0.10 & 28 & 3
\end{tabular}

has been established at input power of $9.6 \mathrm{w}$, with methane conversion up to $31.4 \%$ and oxygen conversion to $36.8 \%$, the stable gas discharge in presence of this catalyst ends up at 


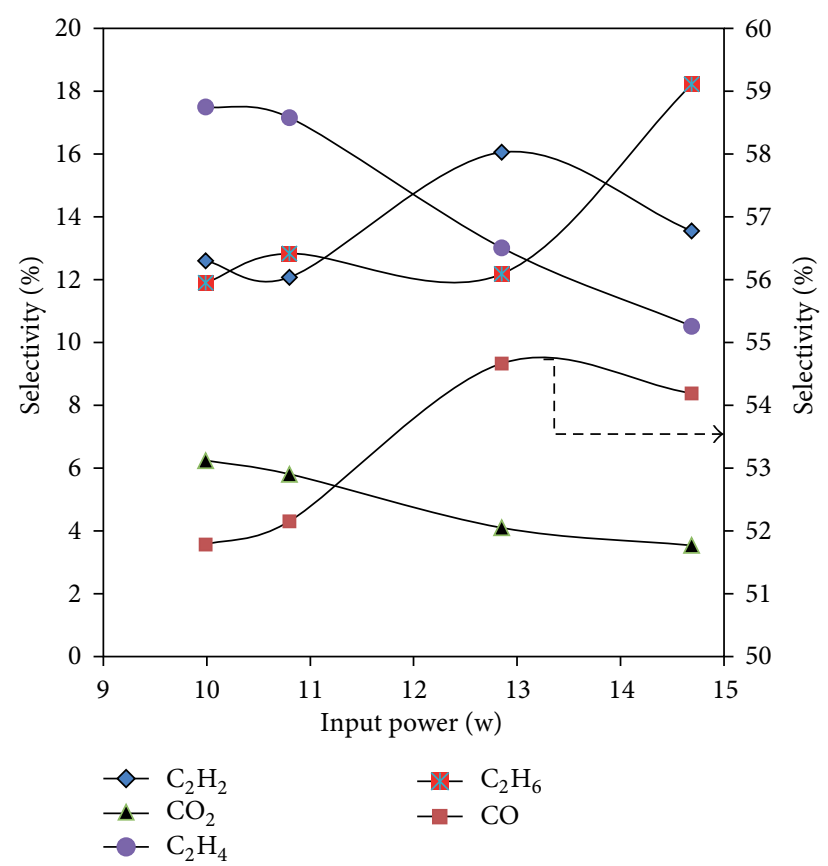

FIGURE 4: Selectivity of products versus input power to the reactor in corona discharge plasma.

input power of $11.3 \mathrm{w}$ with methane and oxygen conversion of $36.8 \%$ and $44.6 \%$ respectively. The catalyst H-ZSM5 also shows enhancement in methane and oxygen conversion upon combined with gas discharge plasma. Presence of these catalysts had the effect of establishing a stable streamer discharge and it is believed that it was the main reason behind the increase of methane and oxygen conversions. The gas discharge shifts to an arc-like discharge more rapidly over FeZSM5 catalyst compared to the other two tested catalysts.

The magnitude of input power is related with the strength of the electric field developed between the electrodes. By increasing the input power to the reactor the number of higher energy electrons that can ionize methane or oxygen molecules increases hence the conversion of $\mathrm{CH}_{4}$ and $\mathrm{O}_{2}$ increases.

4.1. Effect of Input Power to Selectivity of Products. The variations of products selectivity due to changes in electrical power consumed in the gas discharge reactor is shown in Figure 4 . The selectivity of acetylene increases to about $16 \%$ at input power of $13 \mathrm{w}$; it reduces to $13.5 \%$ at power levels above $14 \mathrm{w}$. The highest selectivity to the most valuable hydrocarbon $\mathrm{C}_{2} \mathrm{H}_{4}$ is about $17.5 \%$ which belongs to input power of around $10 \mathrm{w}$, at higher power imparted to the reactor the selectivity to ethylene decreases. Selectivity to saturated hydrocarbon $\mathrm{C}_{2} \mathrm{H}_{6}$ is enhanced by applying higher input power to the reactor; it reaches to more than $18 \%$ at input powers around $14 \mathrm{w}$.

The selectivity of CO is comparatively high and above $50 \%$ and doesn't change much with variations in input power

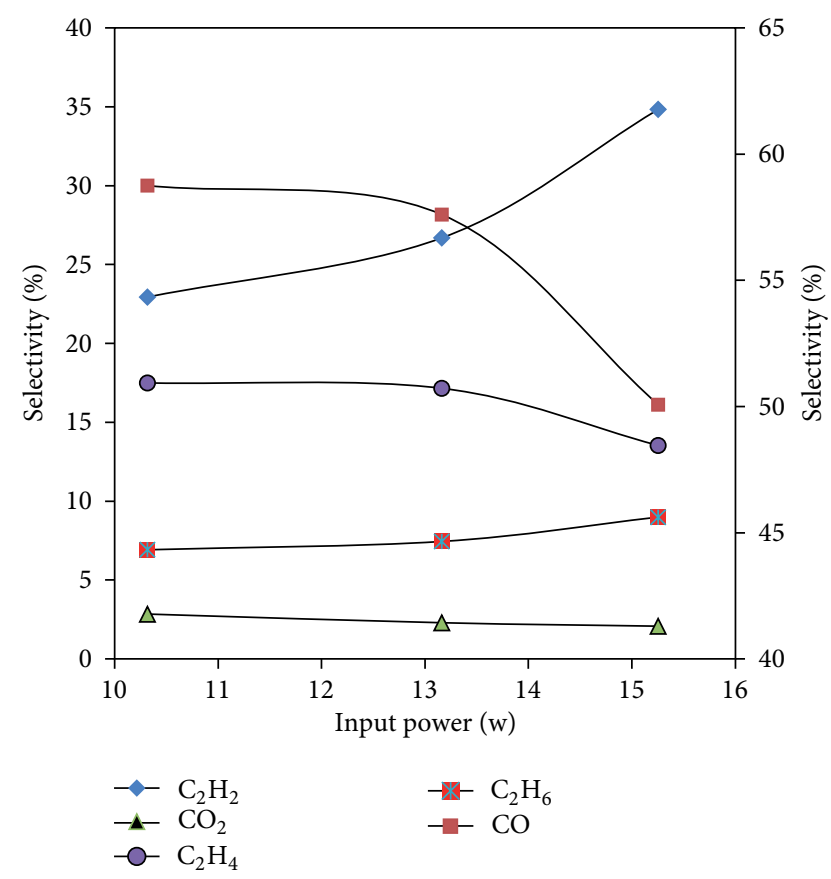

FIGURE 5: Selectivity of products versus input power supplied to the reactor over combined ZSM5 and corona discharge plasma.

to the reactor. As $\mathrm{CO}$ productions is always accompanied with $\mathrm{H}_{2}$ gas according to the following equation:

$$
\mathrm{CH}_{4}+\frac{1}{2} \mathrm{O}_{2} \longrightarrow \mathrm{CO}+2 \mathrm{H}_{2}
$$

Thus the whole process goes to produce $\mathrm{C}_{2}$ hydrocarbons and synthsis gas $\left(\mathrm{CO}+\mathrm{H}_{2}\right)$. The selectivity to unwanted carbon dioxide was however very low.

In another experiment, zeolite ZSM5 was brought into the reactor to investigate its combined effect with gas discharge plasma. Variations of products selectivity over this catalyst versus electrical power consumed in the reactor are shown in Figure 5. The main feature of this catalyst is high selectivity to acetylene, the selectivity of this component increases from $23 \%$ at $10.5 \mathrm{w}$ to about $34.8 \%$ at $15 \mathrm{w}$. It can be concluded that the acidic nature of ZSM5 catalyst is the main source of methane dehydrogenation in plasma environment and hence increase in acetylene selectivity. Selectivity to ethane however is not remarkable; the highest selectivity to this product is about $9 \%$. The selectivity to $\mathrm{CO}$ is 58.7 at $10.5 \mathrm{w}$; it reduces to $50 \%$ at input power of $15.2 \mathrm{w}$. Selectivity to unwanted $\mathrm{CO}_{2}$ gas is however below $3 \%$.

In the next series of experiments Ni-ZSM5 catalyst was placed into the reactor to investigate its combined effect with gas discharge plasma. The variations in the products selectivity versus consumed power in the reactor are shown in Figure 6. The effect of this catalyst is enhanced in acetylene selectivity up to $24.4 \%$ and CO gas up to $66.2 \%$.

When using Fe-ZSM5 as the catalyst combined with gas discharge plasma the results were noticeable. Figure 7 


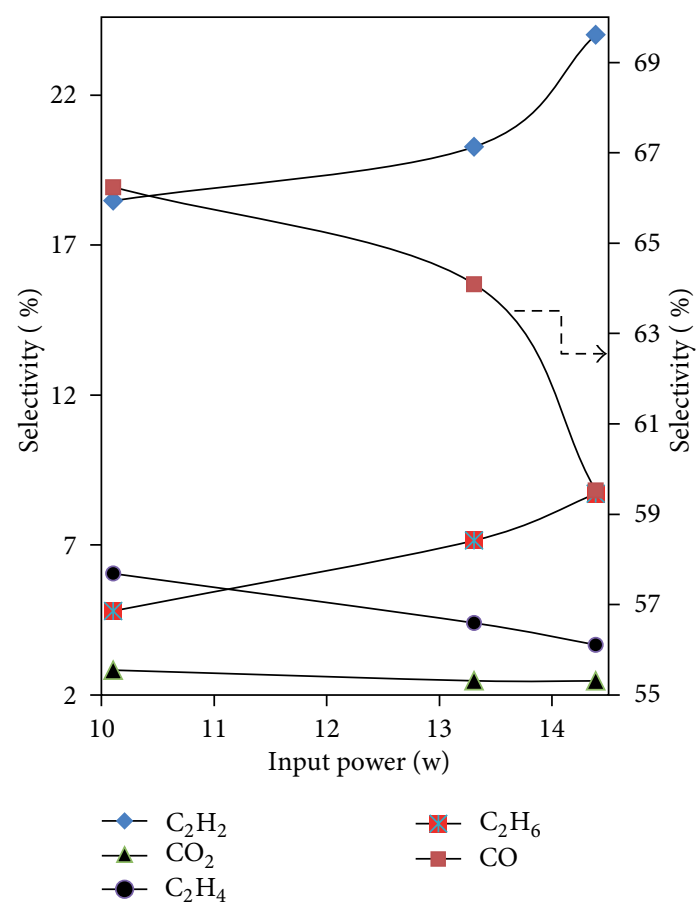

FIGURE 6: Selectivity of products versus power applied to the reactor over combined Ni-ZSM5 catalyst and gas discharge plasma.

demonstrates at input power of $10.4 \mathrm{w}$, the selectivity to $\mathrm{C}_{2} \mathrm{H}_{2}$, $\mathrm{C}_{2} \mathrm{H}_{4}$ and $\mathrm{C}_{2} \mathrm{H}_{6}$ were $18.7 \%, 25.9 \%$ and $13.5 \%$ respectively. As the input power increases the selectivity to $\mathrm{C}_{2} \mathrm{H}_{4}$ continuously decreases to $19.4 \%$ at $14.7 \mathrm{w}$ while the selectivity to $\mathrm{C}_{2} \mathrm{H}_{2}$ and $\mathrm{C}_{2} \mathrm{H}_{6}$ at the same input power is $21 \%$ and $19.4 \%$ respectively. The selectivity of CO is below $40 \%$ and production of synthesis gas was not dominant. The selectivity of $\mathrm{CO}_{2}$ was however low and below $3 \%$.

4.2. Yields of $\mathrm{C}_{2}$ Hydrocarbons. The changes of total yield of $\mathrm{C}_{2}$ hydrocarbons versus variations in power injected to the discharge reactor are shown in Figure 8. Compared with the gas discharge plasma as the only catalytic agent the ZSM5 has the effect of increasing the yield of $\mathrm{C}_{2}$ hydrocarbons combined with the gas discharge plasma. In contrary the catalyst Ni-ZSM5 has effect of reducing yield of higher hydrocarbons compared with gas discharge plasma as the only catalytic effect. Introducing of Fe-ZSM5 to the plasma reactor is totally different this catalyst not only improves the yield of higher hydrocarbons to $20.3 \%$ at an input power of $9.6 \mathrm{w}$ but also the stable gas discharge plasma initiates at lower levels of input power relative to other two catalyst and gas discharge without the presence of external catalyst.

\section{Energy Efficiency}

Figure 9 demonstrates the calculated energy efficiency of gas discharge plasma and three tested catalysts combined with gas discharge to convert one millimole of $\mathrm{CH}_{4}$ to higher

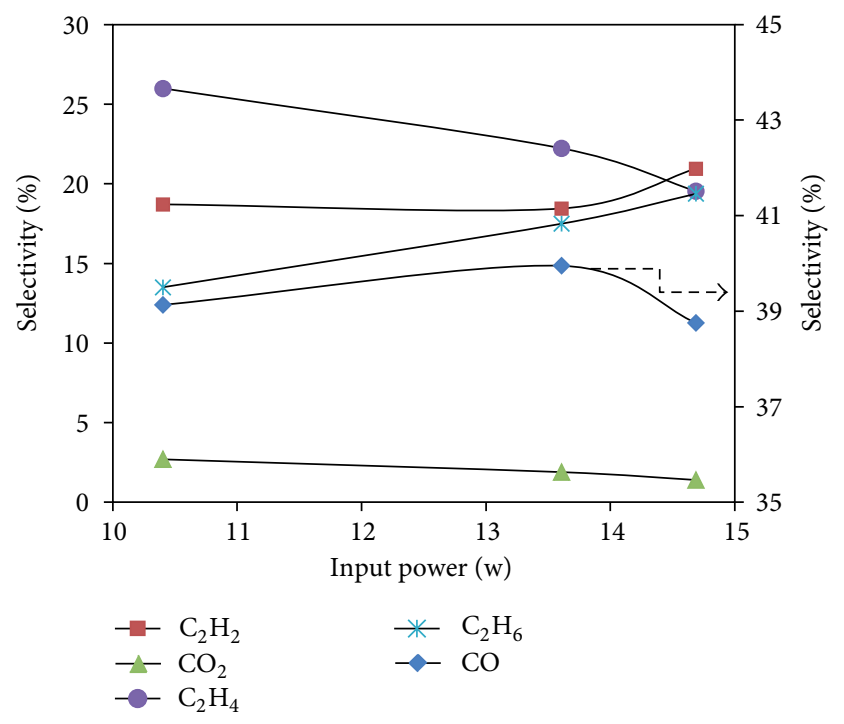

FIGURE 7: Selectivity of products versus power applied to the reactor over Fe-ZSM5 catalyst in plasma environment.

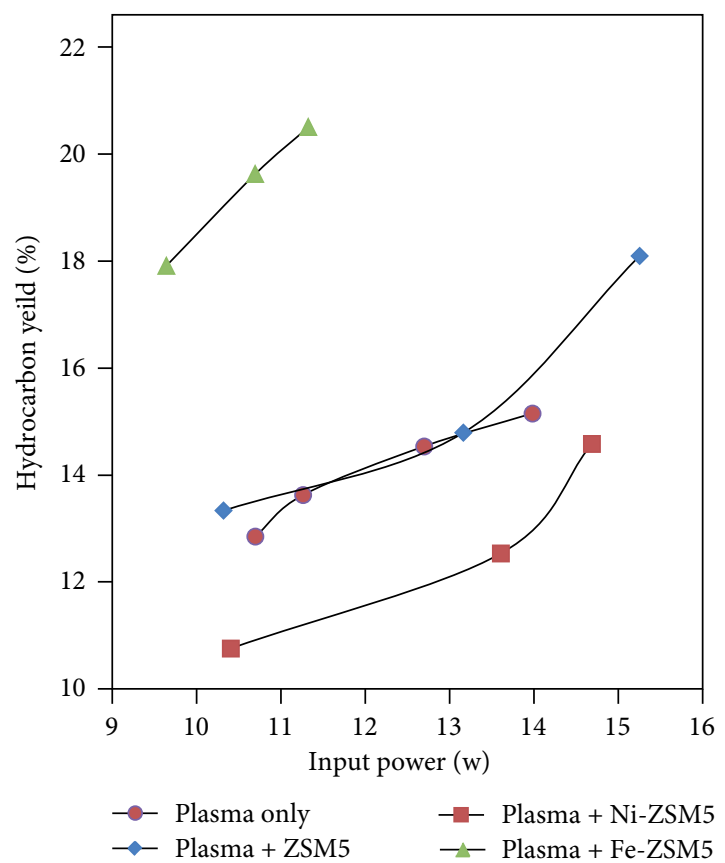

Figure 8: The yield of higher hydrocarbons versus input power supplied to the corona discharge reactor.

hydrocarbons and $\mathrm{CO}_{x}$ products. It is clear that the energy efficiency decreases at higher power imparted to the reactor irrespective of presence or absence of a catalyst in discharge reactor. The power supplied to the reactor at higher levels goes to heating up the bulk gas instead of increasing the kinetic energy of the electrons. The Fe-ZSM5 catalyst has reduced the values of energy efficiency in lower levels of power consumptions in the reactor but at the same time the 


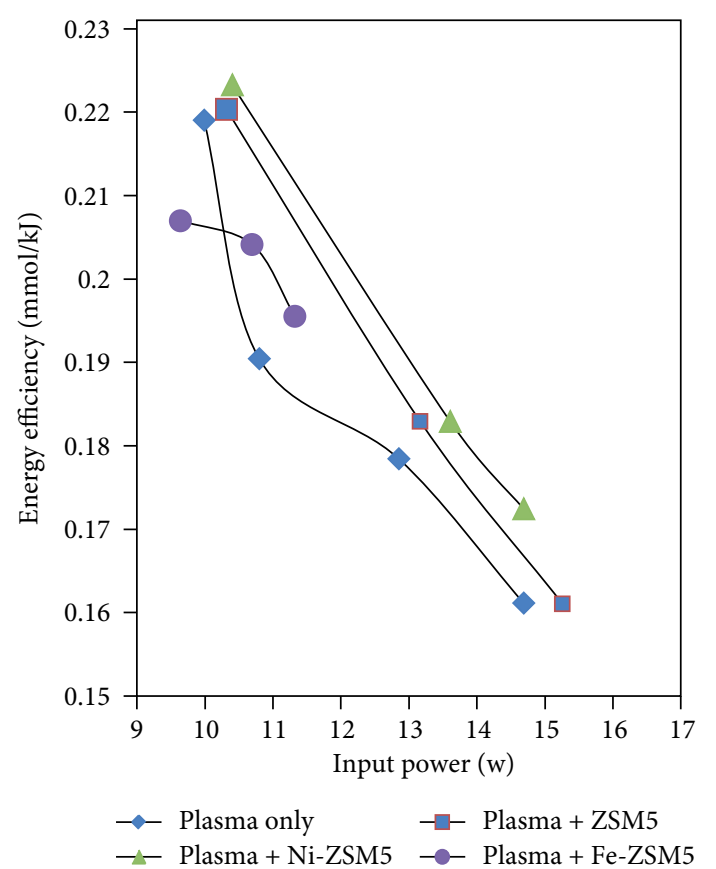

FIGURE 9: Energy efficiency versus input power supplied to the reactor.

extent of changes in the values of energy efficiency verses power to the reactor is limited to a small range. The Ni-ZSM also improves the energy efficiency to $0.22 \mathrm{mmol} / \mathrm{kJ}$ at input power of $10.4 \mathrm{w}$ but the least energy efficiency for this catalyst is 0.17 at an input power of $14.7 \mathrm{w}$ which stands after FeZSM5 in higher input power to the reactor. The catalyst ZSM5 exhibits poor performance at higher input powers to the reactor as it shows $0.16 \mathrm{mmol} / \mathrm{kJ} 15.2 \mathrm{w}$. The energy efficiency of the gas discharge when there is no external catalyst in the reactor is high especially at lower levels of input power to the reactor. The energy efficiency for this catalyst is from 0.19 to $0.16 \mathrm{mmol} / \mathrm{kJ}$ for an input power of 10.8 to $14.7 \mathrm{w}$ respectively.

Table 2 compares different cold plasma systems used to convert methane to more valued products [15].

\section{Conclusions}

Methane conversion which is the main constituent of natural gas to more valued products with ac corona discharge was investigated. The experiments were carried out in a quartz reactor with two parallel plate electrodes. In all experiments the rate of methane conversion was increased with the rate of electric power consumed in the reactor. The chemical inertness of alkens is generally overcome by the use of high temperatures and strongly acidic catalyst such as $\mathrm{H}$ Zeolites or its metal exchanged catalysts. In this study instead of heating the zeolite based catalyst at high temperature the catalysts were placed in a strong electric field instead. The strong electric field changes the electrical properties of the surface of the catalyst and the conversion of methane takes place at temperatures below $200^{\circ} \mathrm{C}$. The yield of $\mathrm{C}_{2}$
TABLE 2: Energy efficiency in different plasma systems for conversion of methane.

\begin{tabular}{lcc}
\hline Plasma & $\begin{array}{c}\text { Conversion } \\
\text { rate } \\
(\mathrm{mmol} / \mathrm{kJ})\end{array}$ & $\begin{array}{c}\text { Background } \\
\text { gas }\end{array}$ \\
\hline Microwave & 0.22 & $\mathrm{CH}_{4}$ \\
Silent & 0.37 & $\mathrm{CH}_{4}+\mathrm{O}_{2}$ \\
AC arc & 0.15 & $\mathrm{CH}_{4}+\mathrm{CO}_{2}$ \\
DC arc & 3.1 & $\mathrm{CH}_{4}+\mathrm{O}_{2}$ \\
Pulsed (240 pps) & 0.36 & $\mathrm{CH}_{4}+\mathrm{O}_{2}$ \\
Pulsed (8 kpps) & 0.68 & $\mathrm{CH}_{4}+\mathrm{CO}_{2}$ \\
Pulsed (8 kpps) reference study & 1.2 & $\mathrm{CH}_{4}$ \\
This study & 0.22 & $\mathrm{CH}_{4}+\mathrm{O}_{2}$ \\
\hline
\end{tabular}

hydrocarbons with Fe-ZSM5 was $20.9 \%$ and the highest energy efficiency in this study was $0.22 \mathrm{mmol} / \mathrm{kJ}$ while using a simple alternative current of $50 \mathrm{~Hz}$. The ac corona discharge can be considered a promising method to convert methane to more valued products. It is a cheap and available technique and does not need very high and sophisticated technology to establish. Furthermore with the catalysts employed in this study it is possible to selectively convert methane to $\mathrm{C}_{2}$ hydrocarbons or synthesis gas.

\section{Disclosure}

This article is original and is not under consideration for publication elsewhere. In addition, the manuscript discusses about conversion of methane to more valued products which is across the spectrum of E-Journal of Chemistry. My coworker in this research (Dr. Mohammad Irani) is aware of the submission and agrees to its publication.

\section{References}

[1] J. H. Lunsford, "Catalytic conversion of methane to more useful chemicals and fuels: a challenge for the 21st century," Catalysis Today, vol. 63, no. 2-4, pp. 165-174, 2000.

[2] A. Holmen, "Direct conversion of methane to fuels and chemicals," Catalysis Today, vol. 142, no. 1-2, pp. 2-8, 2009.

[3] J. R. Rostrup-Nielsen, "Production of synthesis gas," Catalysis Today, vol. 18, no. 4, pp. 305-324, 1993.

[4] H. Schulz, "Short history and present trends of Fischer-Tropsch synthesis," Applied Catalysis A, vol. 186, no. 1-2, pp. 3-12, 1999.

[5] A. Nakhaei Pour, M. R. Housaindokht, S. F. Tayyari, J. Zarkesh, and M. R. Alaei, "Deactivation studies of Fischer-Tropsch synthesis on nano-structured iron catalyst," Journal of Molecular Catalysis A, vol. 330, no. 1-2, pp. 112-120, 2010.

[6] C. Liu, A. Marafee, R. Mallinson, and L. Lobban, "Methane conversion to higher hydrocarbons in a corona discharge over metal oxide catalysts with OH groups," Applied Catalysis A, vol. 164, no. 1-2, pp. 21-33, 1997.

[7] C. J. Liu, R. Mallinson, and L. Lobban, "Nonoxidative methane conversion to acetylene over zeolite in a low temperature plasma," Journal of Catalysis, vol. 179, no. 1, pp. 326-334, 1998.

[8] A. Marafee, C. Liu, G. Xu, R. Mallinson, and L. Lobban, "An experimental study on the oxidative coupling of methane in a 
direct current corona discharge reactor over $\mathrm{Sr} / \mathrm{La}_{2} \mathrm{O}_{3}$ Catalyst," Industrial and Engineering Chemistry Research, vol. 36, no. 3, pp. 632-637, 1997.

[9] L. M. Zhou, B. Xue, U. Kogelschatz, and B. Eliasson, "Partial oxidation of methane to methanol with oxygen or air in a nonequilibrium discharge plasma," Plasma Chemistry and Plasma Processing, vol. 18, no. 3, pp. 375-393, 1998.

[10] C. J. Liu, R. Mallinson, and L. Lobban, "Comparative investigations on plasma catalytic methane conversion to higher hydrocarbons over zeolites," Applied Catalysis A, vol. 178, no. 1, pp. 17-27, 1999.

[11] B. Eliasson, C.-J. Liu, and U. Kogelschatz, "Direct conversion of methane and carbon dioxide to higher hydrocarbons using catalytic dielectric-barrier discharges with zeolites," Industrial and Engineering Chemistry Research, vol. 39, no. 5, pp. 1221-1227, 2000.

[12] F. M. Aghamir, N. S. Matin, A. H. Jalili, M. H. Esfarayeni, M. A. Khodagholi, and R. Ahmadi, "Conversion of methane to methanol in an ac dielectric barrier discharge," Plasma Sources Science and Technology, vol. 13, no. 4, pp. 707-711, 2004.

[13] M. S. H. Tarverdi, Y. Mortazavi, A. A. Khodadadi, and S. Mohajerzadeh, "Synergetic effects of plasma, temperature and diluant on nonoxidative conversion of methane to $\mathrm{C}^{2+}$ hydrocarbons in a dielectric barrier discharge reactor," Iranian Journal of Chemistry and Chemical Engineering, vol. 24, no. 4, pp. 63-71, 2005.

[14] S. L. Yao, E. Suzuki, N. Meng, and A. Nakayama, "Influence of rise time of pulse voltage on the pulsed plasma conversion of methane," Energy and Fuels, vol. 15, no. 5, pp. 1300-1303, 2001.

[15] S. Yao, E. Suzuki, and A. Nakayama, "A novel pulsed plasma for chemical conversion," Thin Solid Films, vol. 390, no. 1-2, pp. 165-169, 2001.

[16] C. Liu, A. Marafee, B. Hill, G. Xu, R. Mallinson, and L. Lobban, "Oxidative coupling of methane with ac and dc corona discharges," Industrial and Engineering Chemistry Research, vol. 35, no. 10, pp. 3295-3301, 1996.

[17] V. R. Choudhary, A. K. Kinage, and T. V. Choudhary, "Lowtemperature nonoxidative activation of methane over $\mathrm{H}$ - galloaluminosilicate (MFI) zeolite," Science, vol. 275, no. 5304, pp. 1286-1288, 1997.

[18] L. Y. Chen, L. W. Lin, Z. S. Xu, X. S. Li, and T. Zhang, "Dehydrooligomerization of methane to ethylene and aromatics over molybdenum/HZSM-5 catalyst," Journal of Catalysis, vol. 157, no. 1, pp. 190-200, 1995. 

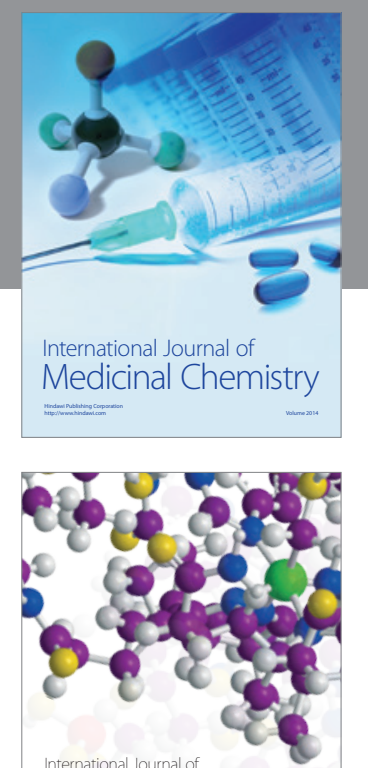

\section{Carbohydrate} Chemistry

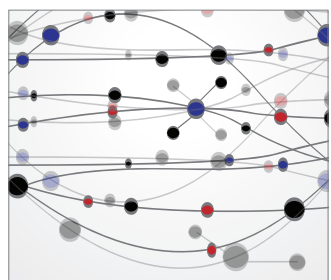

The Scientific World Journal
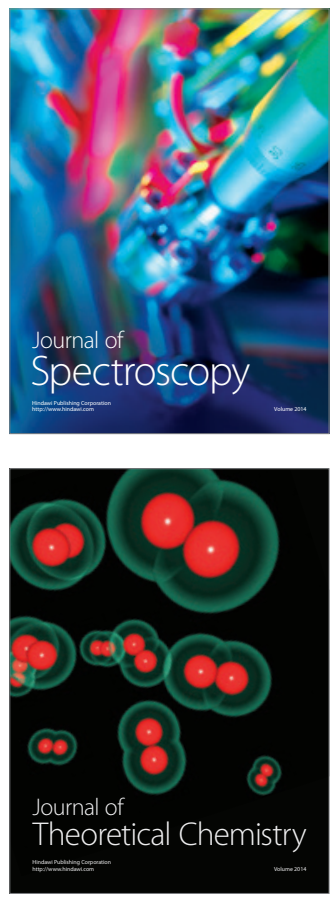
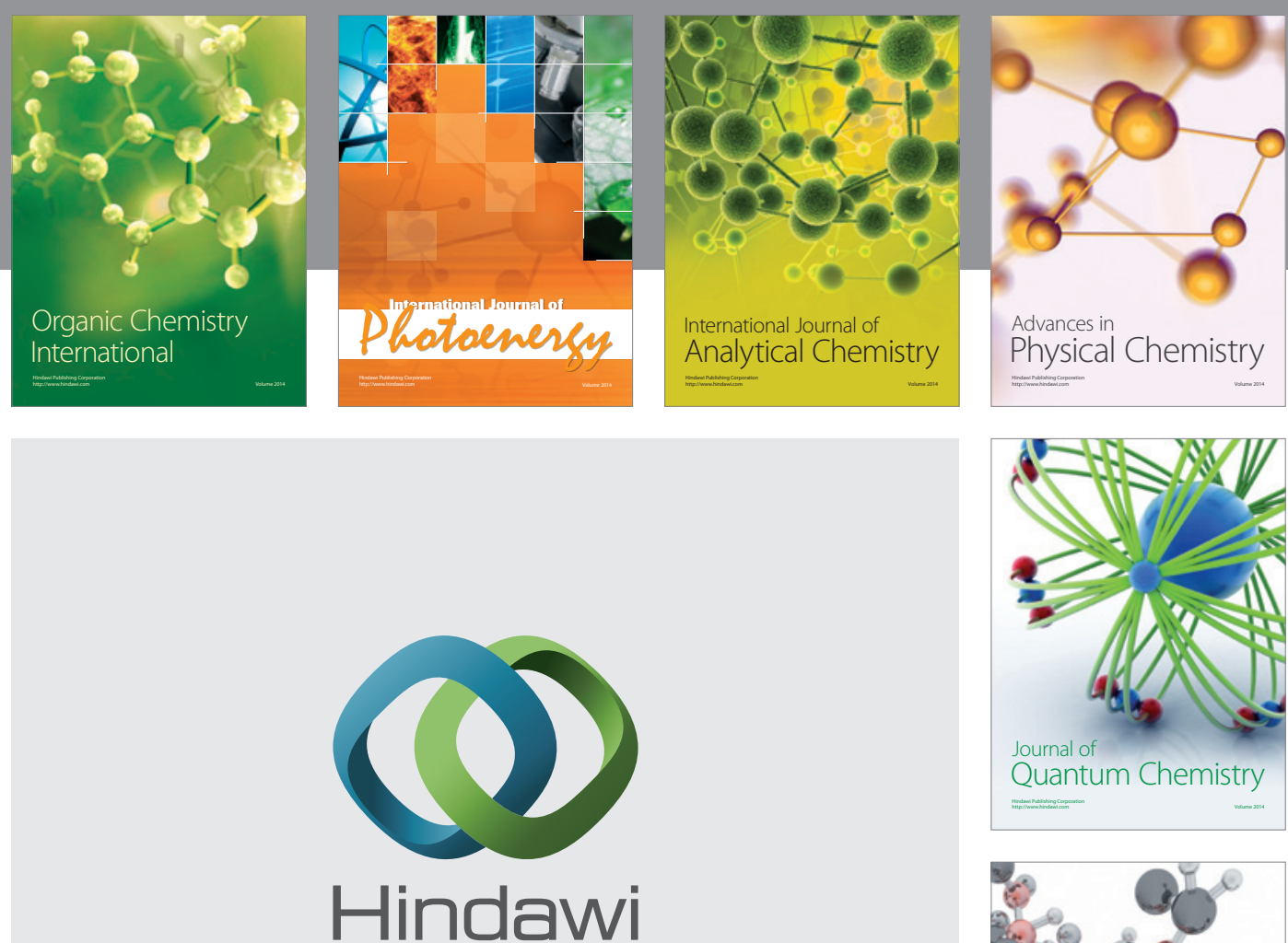

Submit your manuscripts at

http://www.hindawi.com

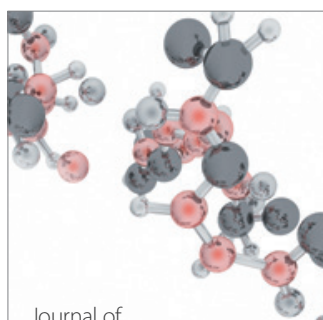

Analytical Methods

in Chemistry

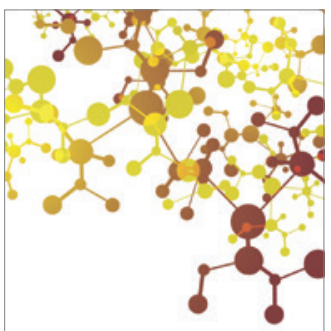

Journal of

Applied Chemistry

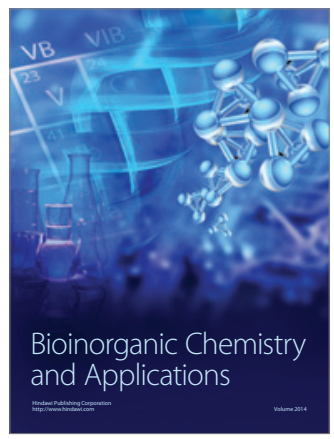

Inorganic Chemistry
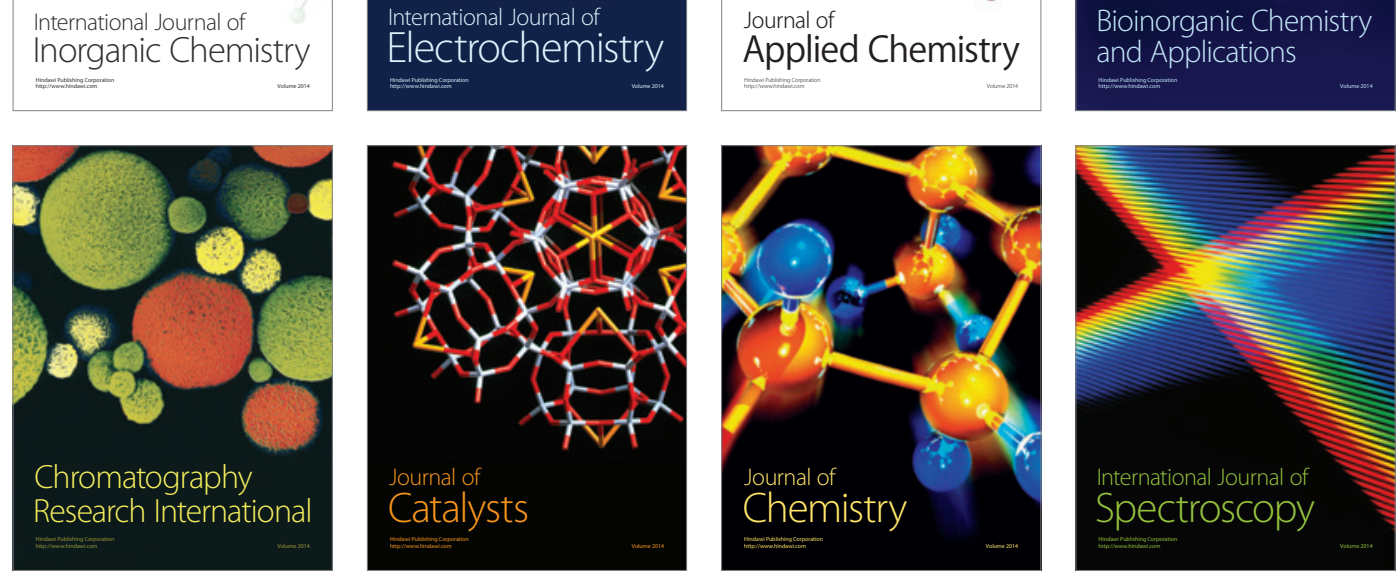